\title{
Article \\ A New Design Method of Shield Tunnel Based on the Concept of Minimum Bending Moment
}

\author{
Dawei Huang ${ }^{1,2}$, Hao Jiang ${ }^{1,2} \oplus$, Changjie $\mathrm{Xu}{ }^{1,2, *}$, Wenbo $\mathrm{Tu}^{1,2},{\mathrm{Xue} \mathrm{Li}^{3} \text { and Wei Wang }}^{1,2}$ \\ 1 Engineering Research Center of Railway Environmental Vibration and Noise, Ministry of Education, \\ East China Jiaotong University, Nanchang 330013, China; gddthdw@126.com (D.H.); \\ jiangh1997@163.com (H.J.); wenbotu@126.com (W.T.); rebwg05@163.com (W.W.) \\ 2 State Key Laboratory of Performance Monitoring and Protecting of Rail Transit Infrastructure, \\ East China Jiaotong University, Nanchang 330013, China \\ 3 School of Geoscience and Technology, Southwest Petroleum University, Chengdu 610500, China; \\ jialixue521@163.com \\ * Correspondence: xucj@zju.edu.cn
}

Citation: Huang, D.; Jiang, H.; Xu, C.; Tu, W.; Li, X.; Wang, W. A New Design Method of Shield Tunnel Based on the Concept of Minimum Bending Moment. Appl. Sci. 2022, 12, 1082. https://doi.org/10.3390/ app12031082

Academic Editors: Mingfeng Lei, Chenjie Gong and Xianda Shen

Received: 31 December 2021

Accepted: 18 January 2022

Published: 20 January 2022

Publisher's Note: MDPI stays neutral with regard to jurisdictional claims in published maps and institutional affiliations.

Copyright: (C) 2022 by the authors. Licensee MDPI, Basel, Switzerland. This article is an open access article distributed under the terms and conditions of the Creative Commons Attribution (CC BY) license (https:// creativecommons.org/licenses/by/ $4.0 /)$.

\begin{abstract}
As the soil-resistance coefficient in a soft soil area is small, overlarge bending moment may cause exceeding transverse deformation for the shield tunnel and cause structural diseases and waterproof failure at the longitudinal segment joints. Hence, a new idea of cross-section design for a minimum bending moment shield tunnel was proposed. This article has first put forward the concept of a zero bending moment shield tunnel. Then, based on rational and feasible hypotheses, a structural mechanical model and an analytical expression of axis for the cross-section of the zero bending moment shield tunnel was obtained, and computational formulas of internal force and key geometry parameters were given. Based on the case of the metro shield tunnel constructed in the Shanghai soft soil area, the zero bending moment shield tunnel was designed, and its characteristics were analyzed. Considering only one cross-section of shield tunnel can be adopted in one metro line, the design method and procedure of the minimum bending moment shield tunnel were put forward. Finally, taking one of the Shanghai metro lines as an example, a cross-section of a minimum bending moment shield tunnel was designed, and its bending moment was compared with the bending moment of a circular section shield tunnel, which had the same horizontal diameter. The comparison revealed that the cross-section of the minimum bending moment can significantly reduce the bending moment of shield tunnel.
\end{abstract}

Keywords: minimum bending moment; cross-section; shield tunnel; soft soil area; design method

\section{Introduction}

The cross-sections for most of the existing shield tunnels all over the world are generally circular [1-4]. Additionally, there are other cross-sections for shield tunnels, such as transverse oval, rectangular, quasi-rectangular (applied in Ningbo Metro Line 3, Zhejiang province, China), semicircle, horseshoe-shaped, double-circle-shaped, and tri-circle-shaped, as shown in Figure 1. The main load for a shield tunnel as an underground structure is the earth pressure [5]. Normally, the tunnel is subjected to larger vertical earth pressure than horizontal earth pressure, and both vertical and horizontal earth pressure increase as the depth of the ground increases. So, the cross-section of a shield tunnel inevitably undertakes bending moment. Especially in the soft soil area, there is little horizontal soil resistance at the side of the tunnel [6-8]. That means that when even lager transverse oval deformation occurs, the difference between the vertical earth pressure and the horizontal earth pressure is large. According to the design specification of metro [9,10], the largest oval deformation for the new constructed shield tunnel upon the acceptance check was 5D\%o, where D represents the outer diameter of the tunnel. However, for some soil conditions, the oval deformation will fail to meet this code, especially in the soft soil area. 


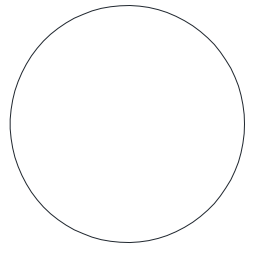

(a)

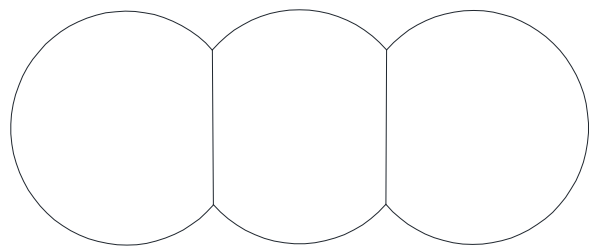

(c)

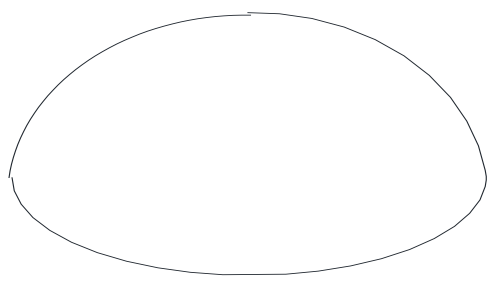

(e)

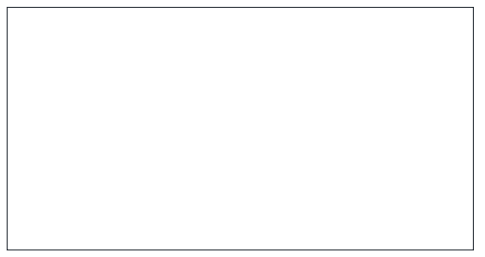

(g)

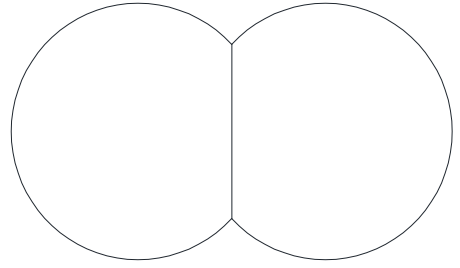

(b)

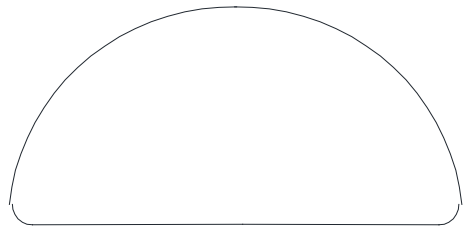

(d)

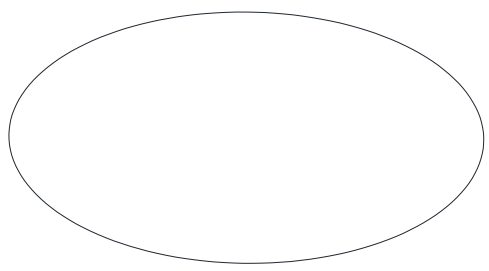

$(\mathbf{f})$

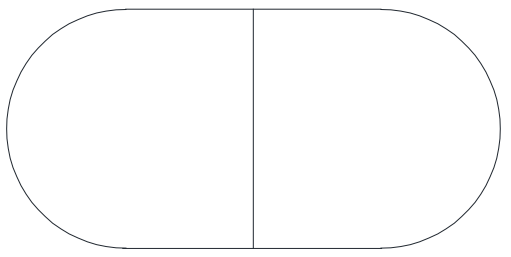

(h)

Figure 1. Typical cross-section of shield tunnels:(a) Circular; (b) Double-circle-shaped; (c) Tri-circleshaped; (d) Semicircle; (e) Horseshoe-shaped; (f) Transverse oval; (g) Rectangular; (h) Quasi-rectangular.

The tunnel is a slender underground structure, so the shield tunnel can be considered as a curved beam structure from the perspective of plane strain, and the length of the curved beam is far larger than the height of the curved beam. The deformation of the beam structure is mainly caused by bending moment. For the cross-section of the shield tunnel, the rotation of the segment longitudinal joint and the bending moment are the main factors that cause transverse oval deformation [11,12]. Besides, when the shield tunnel is under the bending moment, the segment longitudinal joints are prone to segment corner damages and will stretch up $[13,14]$, which will reduce the pressure stress on the waterproof sealing washer or, even worse, the waterproof sealing washer will completely open, causing joint waterproof failure [15-18]. Figure 2 shows the excessive deformation of the segmental joints and the related water-leakage issues. Besides this, under bending moment, the connecting bolts at the segment longitudinal joints will be stretched. Under the over-large bending moment, plastic deformation will occur for the thread of the connecting bolts, causing damages to the segment longitudinal joints [19-22]. One study [23] found that the segment joints were the weak parts of the test structure, through a full-scale test analysis of the bearing capacity of the shield tunnel structure assembled by joints, and the plastic development of the segment joints easily caused structural damage. It illustrates that most of the diseases are caused by the bending moment of the cross-section of the shield tunnel $[19,24-26]$. In all of the existing studies, the properties of a determined section of shield tunnel, as well as for other underground structures, such as culvert pipe 
and underground pipe (most of the pipe in the ground is circular), have been analyzed, but whether the cross-section is suitable for resisting transverse deformation has not been taken into consideration. From the above-mentioned diseases caused by bending moment, it is necessary to design a rational cross-section in order to decrease the bending moment as much as possible.

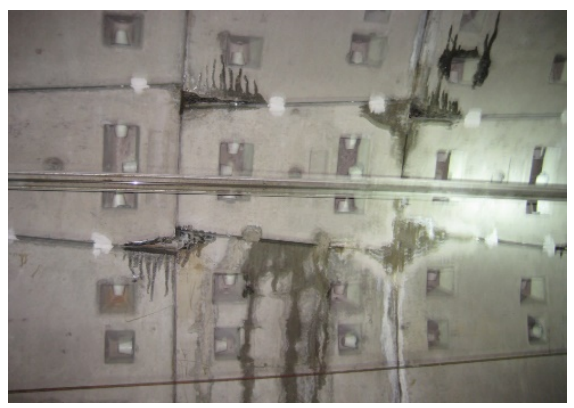

(a)

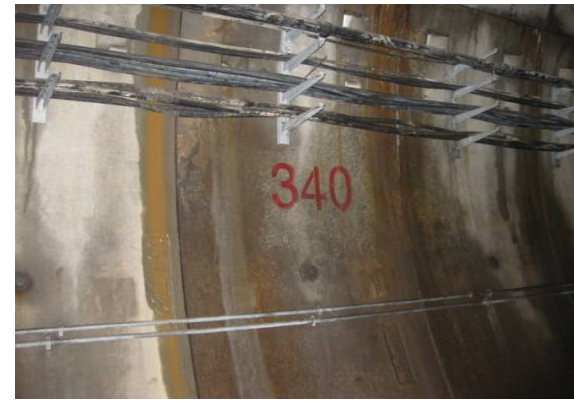

(b)

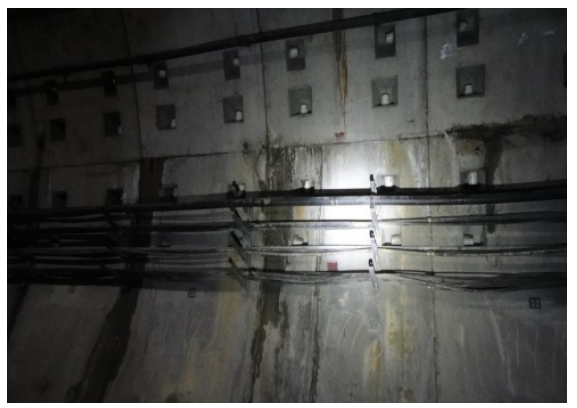

(c)

Figure 2. The excessive deformation and related water-leakage of longitudinal segment joints: (a) The excessive deformation of the segmental joint; (b) Longitudinal segment joint water-leakage; (c) Segment corner water-leakage.

Hence, if a kind of shield tunnel cross-section can be designed so that the theoretical bending moment for any section is zero (namely "zero bending moment shield tunnel"), the above-mentioned diseases of shield tunnels can be solved, which also contributes to the reduction in segment reinforcement. In this article, a new idea of cross-section design for a minimum bending moment shield tunnel is proposed. First, we put forward the concept of a zero bending moment shield. Then, based on rational and feasible hypotheses, a structural mechanical model and analytical expression of the axis for the cross-section of the zero bending moment shield tunnel were obtained, and computational formulas of internal force and key geometry parameters were given. Then, based on the case of the metro shield tunnel constructed in the Shanghai soft soil area, the zero bending moment shield tunnel was designed, and its characteristics were analyzed. Considering that only one cross-section of shield tunnel can be adopted in one metro line, the design method and procedure of the minimum bending moment shield tunnel have been put forward. Finally, taking one of the Shanghai metro lines as an example, the cross-section of the minimum bending moment shield tunnel has been designed. The pioneering work performed here shows that a rational cross-section can greatly decrease the bending moment for underground structures. For shield tunnels or buried pipe, the minimum bending moment cross-section is similar to a vertical ellipse. The research results can be used as a reference for the design of a shield tunnel or other underground structures.

\section{Analysis of the Pressure Exerted on the Cross-Section of the Shield Tunnel \\ 2.1. Hypothesis of the Earth Pressure Acting on the Shield Tunnel}

According to structural mechanics, the rational axis (any section of the axis without bending moment) of the arch is related to the loads that it bears. Since the vertical earth pressure in the stratum is larger than the horizontal earth pressure, when the bending moment of the cross-section of the shield tunnel is zero, the horizontal diameter should not be equal to the vertical diameter. Therefore, when designing the reasonable axis of a shield tunnel section (the bending moment at any section is zero), only the normal condition is considered, which is convenient for analysis and calculation. The hypotheses on the loading of the shield tunnel have been made, as follows:

(1) There is no horizontal soil resistance.

There is zero bending moment in the designed shield tunnel cross-section. Hence, it can be approximately considered that no deformation takes place in the shield tunnel and there is no horizontal soil resistance at the two sides of the tunnel. 
(2) Do not consider the weight of the shield tunnel structure.

As an underground structure bearing the soil pressure, the weight of the shield tunnel is much smaller than the surrounding earth pressure that it bears. According to the design specification of metro [10], the lining thickness should be 0.04 0.06 times larger than the outer contour diameter of the tunnel and the buried depth is much larger than the thickness of the segment. Hence, the bending moment of the tunnel structure that is caused by the weight of tunnel is much smaller than the bending moment of the tunnel structure that is caused by the surrounding earth pressure.

(3) Calculate the vertical earth pressure based on the earth-pillar theory and do not consider the water pressure.

The soil is soft in the soft soil area, and it is impossible to make an arch. Also, the permeability coefficient is small.

Based on the above hypotheses, the earth pressure surrounding the shield tunnel is demonstrated in Figure 3. The pressure can be calculated as Equations (1)-(3).

$$
\begin{gathered}
P_{1}=\gamma H \\
P_{2}=\gamma H k=P_{1} k \\
P_{3}=\gamma a k
\end{gathered}
$$

where $a$ is the vertical diameter of the shield tunnel, $b$ is the horizontal diameter at the center of the vertical diameter of the shield tunnel, $P_{1}$ is the vertical earth pressure, $P_{2}$ is the horizontal earth pressure on top of the tunnel, $P_{3}$ is the part of earth pressure that occurs where the earth pressure at the bottom of the tunnel exceeds the earth pressure on top of the tunnel, $\gamma$ is the volume weight of the soil in the stratum. For the layers of soil, take the average volume weight, $H$ is the buried depth of the tunnel, $k$ is the lateral earth pressure coefficient.

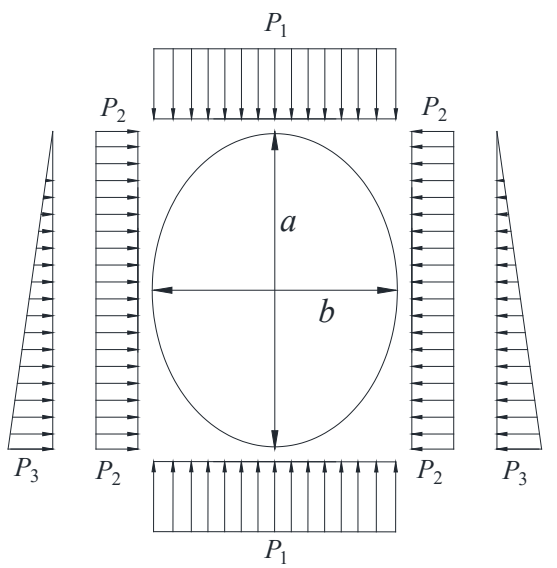

Figure 3. Load distribution of shield tunnel.

\subsection{The Analysis of the Pressure Exerted on the Shield Tunnel}

The simplified earth pressure unit is line loading (such as $\mathrm{kN} / \mathrm{m}$ ), the value of which equals to the earth pressure value in a $3 \mathrm{D}$ condition (the unit is the unit for plane loading, such as $\mathrm{kN} / \mathrm{m}^{2}$ ). It can be learnt from Figure 3 that the structural mechanics model of the way that the shield tunnel plane is subjected to pressure is the same as how symmetrical structure subjects to symmetrical loading, which means analysis of one part will be enough. In order to facilitate the structural mechanics analysis, the semi-structural analysis of Figure 3, after clockwise rotation of 90 degrees, was analyzed, and the corresponding structural mechanics model is shown in Figure 4. From the symmetrical relationship of the structure, loading, and $\Sigma X=0$, it can be assumed that the shear force at cross-section $\mathrm{A}$ $Q_{1}$ and $B Q_{2}$ are both zero. Hence, it is required to design and calculate the axial equation for the zero bending moment of the shield tunnel. Assuming the bending moment of 
cross-section A and cross-section B are both zero, the calculation model of the structural mechanics of the rational axis of the shield tunnel cross-section is demonstrated in Figure 5.

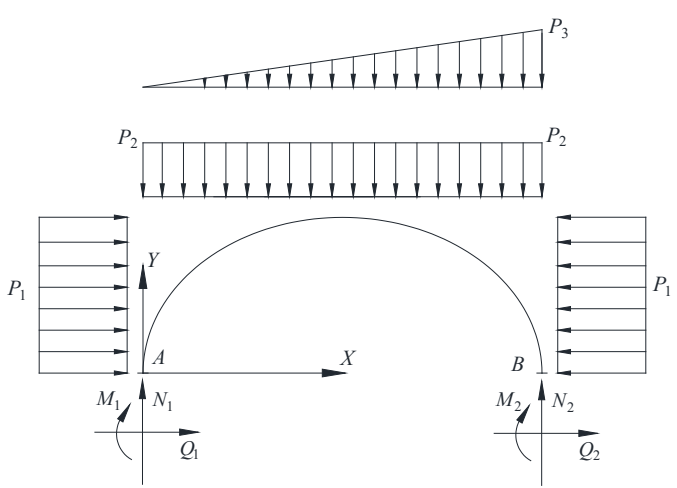

Figure 4. Structural mechanical model of semi-shield tunnel cross-section (the semi-structure of Figure 3, after rotating clockwise 90 degrees).
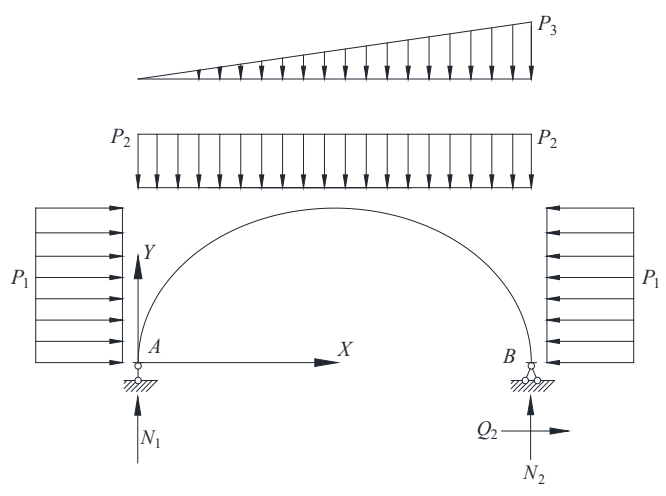

Figure 5. Structural mechanical model of rational axis for zero bending moment shield tunnel cross-section.

Based on $\sum M_{A}=0$ and $\Sigma Y=0$, the axial force can be calculated as Equations (4) and (5).

$$
\begin{aligned}
& N_{1}=\frac{1}{2} P_{2} a+\frac{1}{6} P_{3} a \\
& N_{2}=\frac{1}{2} P_{2} a+\frac{1}{3} P_{3} a
\end{aligned}
$$

where $N_{1}$ is the axial force of cross-section A and $N_{2}$ is the axial force of cross-section B.

\section{The Design and Calculation of the Zero Bending Moment Shield Tunnel Cross-Section}

3.1. The Calculation of the Rational Axis for Shield Tunnel Cross-Section

The expression of the rational axis is required to be calculated when designing the rational axis for the shield tunnel cross-section. In Figure 5, the left cross-section of the shield tunnel is cross-section $S$, and its coordinate is $(x, y)$. As in Figure 6, cross-section $S$ is composed of four parts, as follows:

$$
M_{s}=N_{1} x-\frac{1}{2} P_{2} x^{2}-\frac{1}{6 a} P_{3} x^{3}-\frac{1}{2} P_{1} y^{2}
$$

where $M_{S}$ is the bending moment of cross-section $S ; x$ is the horizontal coordinate of cross-section $S ; y$ is the vertical coordinate of cross-section $S$. 


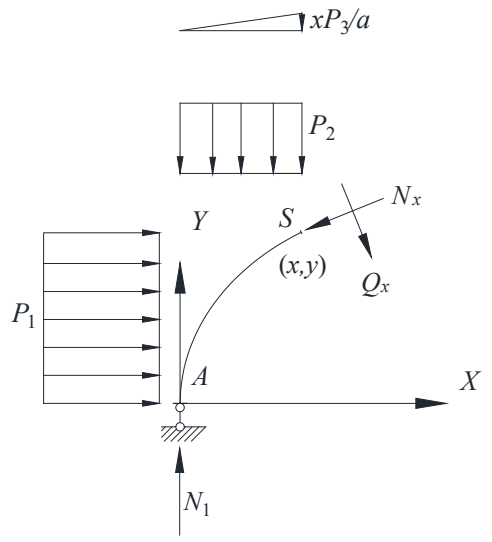

Figure 6. Internal force analysis for a section of zero bending moment shield tunnel cross-section 1.

Equation (6) shows that the first three bending moments $M_{S}$ are all caused by the loading on the $Y$-axis and the values are only associated the value of $x$; the fourth $M_{S}$ is caused by the loading along the $X$-axis, the value of which is only related with $y$. The first three bending moments and the corresponding simply supported beam (as shown in Figure 7) share the shame bending moment expression when subjected to the same loading along the $Y$-axis. Assuming the bending moment expression of the simply supported beam at horizontal coordinate $x$ is as follows:

$$
M_{x}=N_{1} x-\frac{1}{2} P_{2} x^{2}-\frac{1}{6 a} P_{3} x^{3}
$$

where $M_{x}$ is the bending moment at the position of horizontal coordinate $x$.

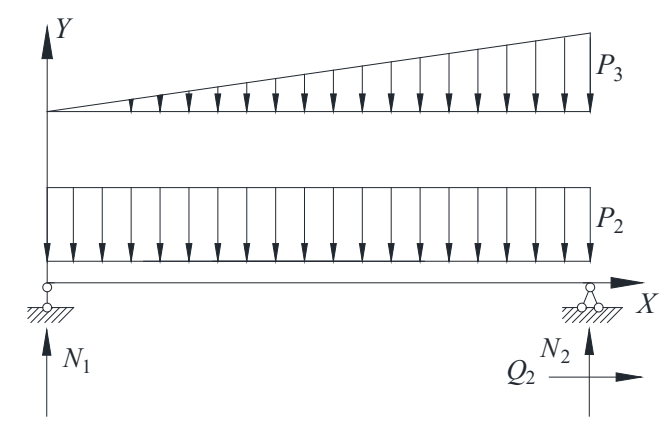

Figure 7. Corresponding simply supported beam model for zero bending moment shield tunnel cross-section.

In order to realize the zero bending moment of the cross-section $S$, the vertical coordinate for cross-section $S$ can be calculated as Equation (8).

$$
y=\sqrt{2 M_{x} / P_{1}}=\sqrt{\left(2 N_{1} x-P_{2} x^{2}-\frac{1}{3 a} P_{3} x^{3}\right) / P_{1}}
$$

However, the bending moment of the right cross-section $S$ is composed of five parts, as shown in Figure 8. The bending moment of the cross-section $S$ on the right of Figure 8 caused by the $P_{1}$ loading in the left direction exerted on curve $C S$ shares the same value as the bending moment of the cross-section $S$ caused by the $P_{1}$ loading in the right direction exerted on curve $D C$ on the left of Figure 8. The two bending moments are in opposite directions so they can offset each other. Therefore, Equation (8) can be applied to any section in Figure 5. 


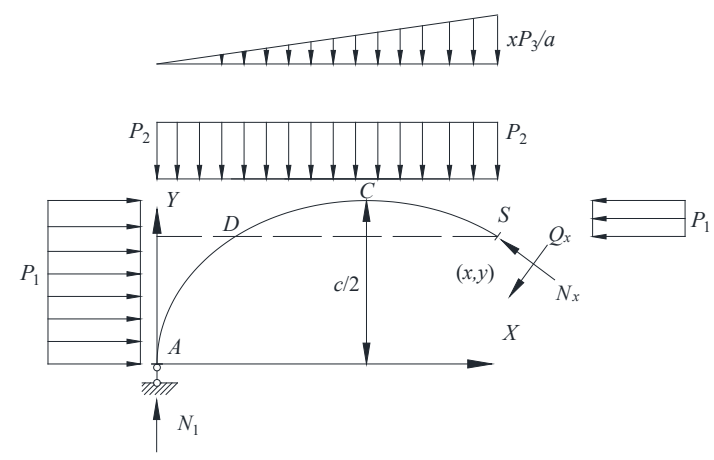

Figure 8. Internal force analysis for a section of zero bending moment shield tunnel cross-section 2.

\subsection{The Calculation of the Horizontal Diameter of the Zero Bending Moment Shield Tunnel}

The horizontal diameter at the center of the vertical diameter of the shield tunnel is known as the center horizontal diameter, represented by $b$. From the calculating equation of the rational axis of the shield tunnel cross-section and the calculating equation of the bending moment of the corresponding simply supported beam, it can be learnt that, since the lateral earth pressure of the shield tunnel is larger at the top than at the bottom, the largest horizontal diameter of the shield tunnel does exist at the vertical diameter center but somewhere lower than the center itself. The largest horizontal diameter of the shield tunnel is represented as $c$.

When $x=a / 2$, the corresponding $y=b / 2$, according to Equation (8), the calculating equation of $b$ be calculated as Equation (9).

$$
b=2 \sqrt{\left(N_{1} a-\frac{1}{4} P_{2} a^{2}-\frac{1}{24} P_{3} a^{2}\right) / P_{1}}
$$

For the maximum of $\beta$, the corresponding $y=c / 2$. The calculating equation of $c$ can thus be obtained. Assume $M_{x}$ is the derivative of $x$ to $x$, as shown in Equation (10).

$$
\beta=\frac{d M_{x}}{d x}=N_{1}-P_{2} x-\frac{1}{2 a} P_{3} x^{2}
$$

From Figure 7 , it can be learnt that $x \in[0, a]$. When $\beta=0$, the corresponding $x$ will obtain the maximum $M_{x}$. Hence, the maximum of $y$ will be obtained based on the corresponding $x$ when $\beta=0$, which is $c / 2$. The value of $x$ conditional on $\beta=0$ can be calculated as Equation (11).

$$
\bar{x}=\frac{a}{P_{3}}\left(\sqrt{P_{2}^{2}+\frac{2}{a} N_{1} P_{3}}-P_{2}\right)
$$

where $x$ is the value corresponding to the condition $\beta=0$.

Put $\bar{x}$ obtained from Equation (11) into Equation (8), to obtain the calculating equation of $c$, as shown in Equation (12).

$$
c=2 \sqrt{\left(2 N_{1} \bar{x}-P_{2} \bar{x}^{2}-\frac{1}{3 a} P_{3} \bar{x}^{3}\right) / P_{1}}
$$

where $c$ is the largest horizontal diameter of the shield tunnel.

Name the distance difference between the position of the vertical diameter conditional on the maximum horizontal diameter and the position of the vertical diameter conditional on the center horizontal diameter as eccentricity $\Delta$. It can be calculated as Equation (13).

$$
\Delta=\bar{x}-\frac{a}{2}
$$


where $\Delta$ is the difference of vertical diameter position under the different conditions.

\subsection{The Calculation of the Internal Force of the Zero Bending Moment Shield Tunnel}

For shield tunnels whose cross-section is rational axis, the internal force of the crosssection is only composed of the axial force and the shear force. Assume that the axial force of the cross-section $S$ is $Q_{x}$ and the shear force is $Q_{x}$. Given that the angle of the section will change as the coordinates change, the internal force of the cross-section $S$ can be disintegrated as the horizontal loading $F_{h x}$ and the vertical loading $F_{v x}$ (in Figure 9 the leftward and the upward are set as positive), as shown in Figure 9. First calculate the position angle of the section $S$, then disintegrate the horizontal loading as $F_{h x}$, vertical loading $F_{v x}$ as axial force $N_{x}$, and shear force $Q_{x}$ (in Figure 8 the pressure exerted on the section $S$ direction and the direction where the slider rotates clockwise are set as positive).

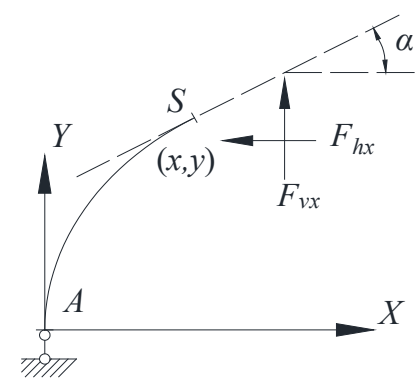

Figure 9. Internal force analysis for a section of zero bending moment shield tunnel cross-section 3.

$\sum X=0, F_{h x}$ is calculated as Equation (14).

$$
F_{h x}=P_{1} y
$$

where $F_{h x}$ is the loading of section $S$ in a horizontal direction.

$F_{v x}, F_{v x}$ is calculated as Equation (15).

$$
F_{v x}=P_{2} x+\frac{P_{3}}{2 a} x^{2}-N_{1}
$$

where $F_{v x}$ is the loading of section $S$ in a vertical direction.

Derivation of Equation (8) to $x, \psi$ is calculated as Equation (16).

$$
\psi=\frac{d y}{d x}=\frac{1}{2 P_{1}} \cdot \sqrt{\frac{P_{1}}{2 N_{1} x-P_{2} x^{2}-\frac{1}{3 a} P_{3} x^{3}}} \cdot\left(2 N_{1}-2 P_{2} x-\frac{1}{a} P_{3} x^{2}\right)
$$

The expression of the angle $\alpha$ can be calculated as Equation (17).

$$
\alpha=\arctan \frac{d y}{d x}=\arctan \psi
$$

where $\alpha$ is the angle between the tangent of cross-section $S$ and the horizontal line.

According to the equivalent relation between $F_{h x}, F_{v x}$, and $N_{x}, \mu, N_{x}, Q_{x}$ can be calculated as Equations (18) and (19).

$$
N_{x}=F_{h x} \cos \alpha-F_{v x} \sin \alpha
$$

where $N_{x}$ is the axial force of cross-section $S$.

$$
Q_{x}=-F_{h x} \sin \alpha-F_{v x} \cos \alpha
$$

where $Q_{x}$ is the shear force of cross-section $S$. 


\section{Cross-Section Design and Case Analysis for Minimum Bending Moment Shield Tunnel in Soft Soil Area}

\subsection{Brief Introduction for Shanghai Metro Shield Tunnel}

Taking the Shanghai soft soil area as an example, the minimum bending moment shield tunnel is designed according to its stratum characteristics, as shown in Figure 10. The circular cross-section tunnel lining of the shield tunnels with non-staggered installation, which is widely used in Shanghai's single-line metro, is assembled with non-staggered installation precast segments. The outer diameter of the segment ring is $6.2 \mathrm{~m}$, and the thickness and width of the segment are $0.35 \mathrm{~m}$ and $1.2 \mathrm{~m}$, respectively. The segment is precast using high-strength concrete (C55 grade), of which the Poisson's ratio and thr elastic modulus are 0.18 and $35.5 \mathrm{GPa}$, respectively. The segment ring is composed of six segments, which is shown in Figure 11. Straight bolts, with a mechanical property grade of 5.8 , are adopted for the circumferential and longitudinal connection of the segment rings.

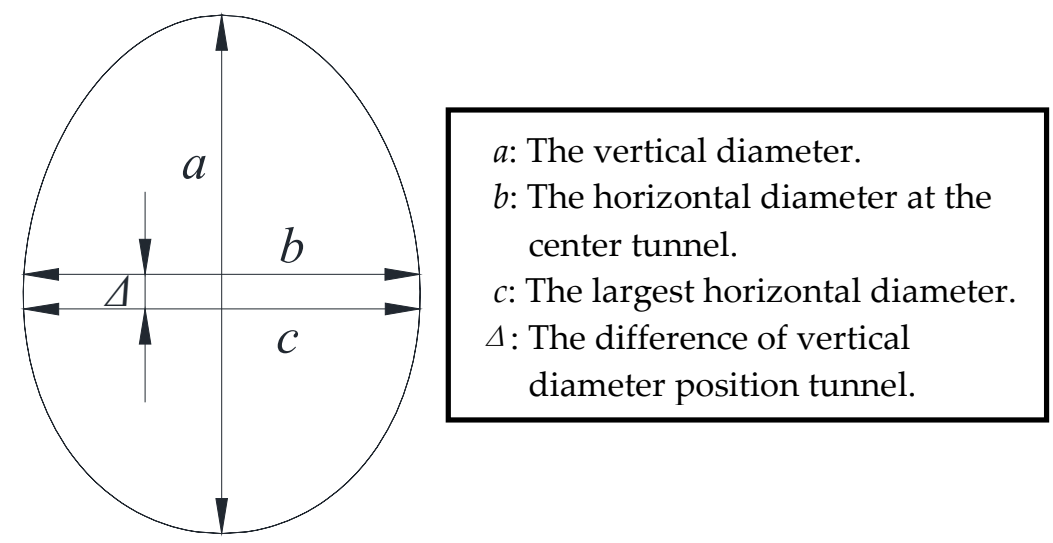

Figure 10. Critical parameters for vertical elliptical cross-section shield tunnel.

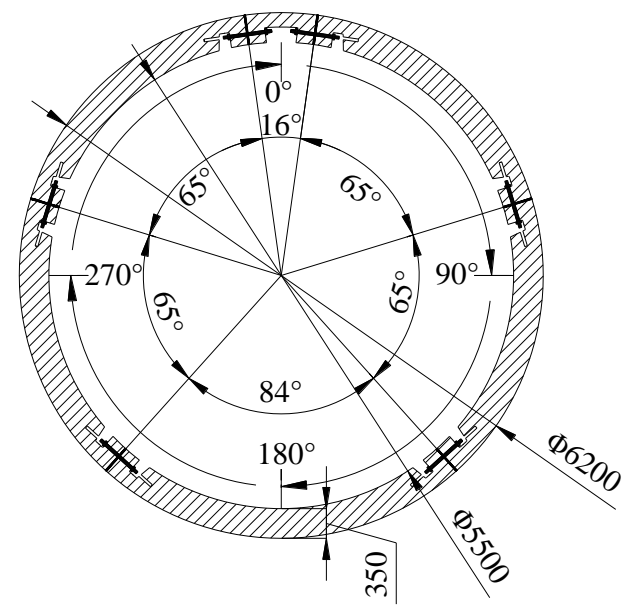

Figure 11. Diagram for structure parameters of shield tunnel in Shanghai (unit: $\mathrm{mm}$ ).

Shanghai, as the representative saturated soft soil ground area in China, has shield tunnels that mainly go through soil (3), (4), (5), (6), especially soil (3), (4). Table 1 shows the physical parameters measured by some engineering test of corresponding stratum. These data indicate that the main soil that the shield tunnel goes through features large water content, large compressibility, and low strength. Such soil also features high sensibility. When a shield tunnel is constructed in such soil, the horizontal soil resistance is very small $[27,28]$, which is one of the reasons why the beyond-limit oval deformation of the shield tunnel easily occurs. So, it is necessary to try to design a rational cross-section of shield tunnels constructed in soft soil with less bending moment. 
Table 1. Shanghai geological soil parameters.

\begin{tabular}{|c|c|c|c|c|c|c|c|c|c|}
\hline Soil Layer & $\begin{array}{c}\text { Unit } \\
\text { Weight } / \mathbf{k N} / \mathrm{m}^{3}\end{array}$ & $\begin{array}{c}\text { Moisture } \\
\text { Content } / \%\end{array}$ & $\begin{array}{l}\text { Void } \\
\text { Ratio }\end{array}$ & $\begin{array}{c}\text { Liquid } \\
\text { Limit/\% }\end{array}$ & $\begin{array}{c}\text { Plastic } \\
\text { Limit } / \%\end{array}$ & Cohesion $/ \mathbf{k P a}$ & $\begin{array}{l}\text { Internal } \\
\text { Friction } \\
\text { Angle }^{\circ}\end{array}$ & $\begin{array}{l}\text { Compression } \\
\text { Modu- } \\
\text { lus/MPa }\end{array}$ & $\begin{array}{c}\text { Poisson } \\
\text { Ratio }\end{array}$ \\
\hline $\begin{array}{l}\text { (3) Mucky } \\
\text { silty clay }\end{array}$ & 19.6 & 39.7 & 1.123 & 35.4 & 20.5 & 9 & 16.5 & 3.36 & 0.3 \\
\hline $\begin{array}{l}\text { (4) Mucky } \\
\text { clay }\end{array}$ & 18.8 & 49.4 & 1.392 & 43.2 & 23 & 13 & 10.5 & 2.27 & 0.33 \\
\hline (5) Silty clay & 20.1 & 34.8 & 0.996 & 36.9 & 20.7 & 17 & 14 & 4.27 & 0.31 \\
\hline (6) Clay & 20.5 & 23.3 & 0.695 & 34 & 18.5 & 44 & 15.5 & 6.58 & 0.3 \\
\hline
\end{tabular}

Suppose the coefficient of lateral earth pressure $k$ is calculated as Equation (20).

$$
k=\frac{\mu}{1-\mu}
$$

where $\mu$ is the Poisson's ratio.

Then the coefficient of lateral earth pressure is $0.4286-0.4925$.

\subsection{Analysis for Cross-Section Key Parameters of Zero Bending Moment Shield Tunnel}

For the properties of soft soil, the vertical earth pressure on the crown of the tunnel is considered as the earth-pillar theory earth pressure, calculated by Equation (1). Assume that the thickness of soil above the tunnel crown is $12 \mathrm{~m}$, the vertical diameter of the crosssection axis of the tunnel is $6 \mathrm{~m}$ (the central axis position of the outer and inner diameter of the tunnel cross-section is taken as the design diameter). The average unit weight of soil is $19.5 \mathrm{kN} / \mathrm{m}^{3}$. According to the proposed design method for the cross-section of the zero bending moment shield tunnel, cross-section key parameters of the zero bending moment are obtained based on different lateral earth pressure coefficients, as shown in Table 2. When the lateral earth pressure coefficient $k$ increases, the eccentric distance $\Delta$ of the zero bending moment shield tunnel remains the same, and the center horizontal diameter $b$ and the maximum horizontal diameter $c$ both increase. Assume that the lateral earth pressure coefficient is 0.46 , cross-section key parameters of the zero bending moment shield tunnel under a different thickness of soil above the tunnel crown is shown in Table 3 . With the increase in the thickness of the soil above the tunnel crowns, the eccentric distance $\Delta$, the center horizontal diameter $b$, and the maximum horizontal diameter $c$ all decrease. The data in Tables 1 and 2 indicate that both the center horizontal diameter $b$ and the maximum horizontal diameter $c$ are smaller than the vertical diameter $a$. The calculation results indicate that there is zero shear force for any section of the cross-section of the zero bending moment, which means that there is no shear deformation at the segment longitudinal joints. The minimum axial force $N_{1}$ is apparent at the crown of the tunnel, and the maximum axial force $N_{3}$ is apparent at the level of maximum horizontal diameter. $N_{2}$ is the axial force at the tunnel invert.

Table 2. Key parameters for no bending moment shield tunnels with different coefficients of lateral earth pressure.

\begin{tabular}{cccccccccccc}
\hline $\boldsymbol{H} / \mathbf{m}$ & $\boldsymbol{k}$ & $\boldsymbol{P}_{\mathbf{1}} \mathbf{k} \mathbf{k P a}$ & $\boldsymbol{P}_{\mathbf{2}} / \mathbf{k P a}$ & $\boldsymbol{P}_{\mathbf{3}} / \mathbf{k P a}$ & $\boldsymbol{a} / \mathbf{m}$ & $\boldsymbol{b} / \mathbf{m}$ & $\boldsymbol{c} / \mathbf{m}$ & $\boldsymbol{N}_{\mathbf{1}} / \mathbf{k N}$ & $\boldsymbol{N}_{\mathbf{2}} / \mathbf{k N}$ & $\boldsymbol{N}_{\mathbf{3}} / \mathbf{k N}$ & $\boldsymbol{\Delta} / \mathbf{m}$ \\
\hline 12 & 0.42 & 222.00 & 93.24 & 46.62 & 6.00 & 4.347 & 4.350 & 326.34 & 372.96 & 482.83 & 0.0997 \\
12 & 0.44 & 222.00 & 97.68 & 48.84 & 6.00 & 4.450 & 4.452 & 341.88 & 390.72 & 494.19 & 0.0997 \\
12 & 0.46 & 222.00 & 102.12 & 51.06 & 6.00 & 4.550 & 4.552 & 357.42 & 408.48 & 505.30 & 0.0997 \\
12 & 0.48 & 222.00 & 106.56 & 53.28 & 6.00 & 4.648 & 4.650 & 372.96 & 426.24 & 516.17 & 0.0997 \\
12 & 0.50 & 222.00 & 111.00 & 55.50 & 6.00 & 4.743 & 4.746 & 388.50 & 444.00 & 526.81 & 0.0997 \\
\hline
\end{tabular}


Table 3. Key parameters for no bending moment shield tunnels with different buried depths.

\begin{tabular}{cccccccccccc}
\hline $\boldsymbol{H} / \mathbf{m}$ & $\boldsymbol{k}$ & $\boldsymbol{P}_{\mathbf{1}} / \mathbf{k P a}$ & $\boldsymbol{P}_{\mathbf{2}} / \mathbf{k P a}$ & $\boldsymbol{P}_{\mathbf{3}} / \mathbf{k P a}$ & $\boldsymbol{a} / \mathbf{m}$ & $\boldsymbol{b} / \mathbf{m}$ & $\boldsymbol{c} / \mathbf{m}$ & $\boldsymbol{N}_{\mathbf{1}} / \mathbf{k N}$ & $\boldsymbol{N}_{\mathbf{2}} / \mathbf{k N}$ & $\boldsymbol{N}_{\mathbf{3}} / \mathbf{k N}$ & $\boldsymbol{\Delta} / \mathbf{m}$ \\
\hline 6 & 0.46 & 111.00 & 51.06 & 51.06 & 6.00 & 4.984 & 4.992 & 204.24 & 255.30 & 277.03 & 0.1652 \\
9 & 0.46 & 166.50 & 76.59 & 51.06 & 6.00 & 4.699 & 4.703 & 280.83 & 331.89 & 391.52 & 0.1244 \\
12 & 0.46 & 222.00 & 102.12 & 51.06 & 6.00 & 4.550 & 4.552 & 357.42 & 408.48 & 505.30 & 0.0997 \\
18 & 0.46 & 333.00 & 153.18 & 51.06 & 6.00 & 4.395 & 4.397 & 510.60 & 561.66 & 732.05 & 0.0713 \\
28 & 0.46 & 518.00 & 238.28 & 51.06 & 6.00 & 4.282 & 4.282 & 765.90 & 816.96 & 1109.14 & 0.0483 \\
\hline
\end{tabular}

The corresponding cross-sections for Tables 1 and 2 are in Figure 12, which are similar to a vertical ellipse. The axial forces for the zero bending moment tunnel are shown as Figure 13 (for the vertical symmetry of the axial forces, only axial forces at the range between $0^{\circ}$ and $180^{\circ}$ are given). The difference values of the horizontal diameters between any cross-sections of the zero bending moment tunnel are smaller than any difference value between the horizontal diameters of the zero bending moment tunnel and circular tunnel. So, any cross-section of the zero bending moment tunnel is adopted for the metro shield tunnel, and its maximum bending moment is smaller than the circular cross-section.

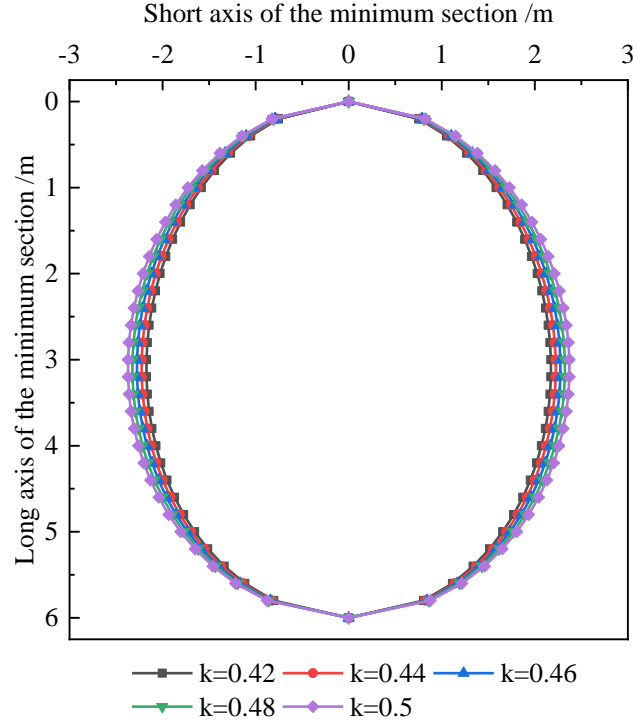

(a)

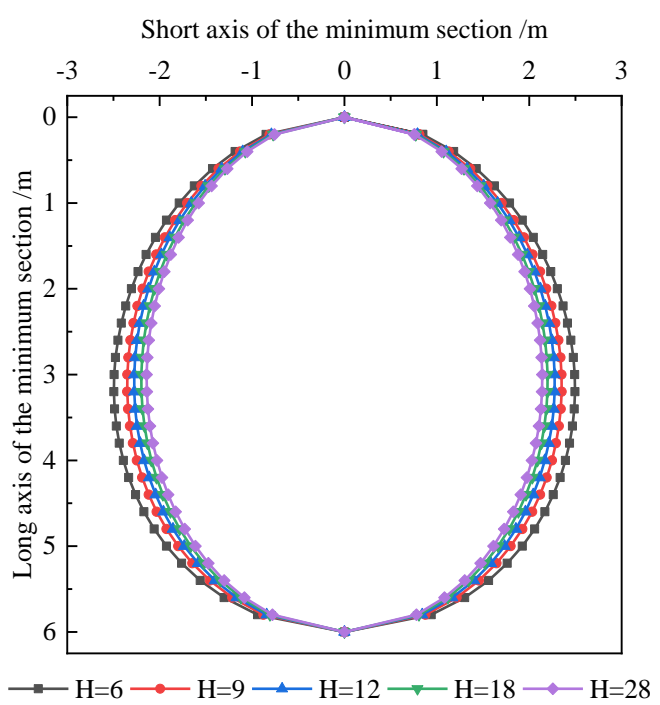

(b)

Figure 12. Zero bending moment shield tunnel cross-section with vertical diameter of $6 \mathrm{~m}$ : (a) Different coefficients of lateral earth pressure; (b) Different thickness of overlaying soil.

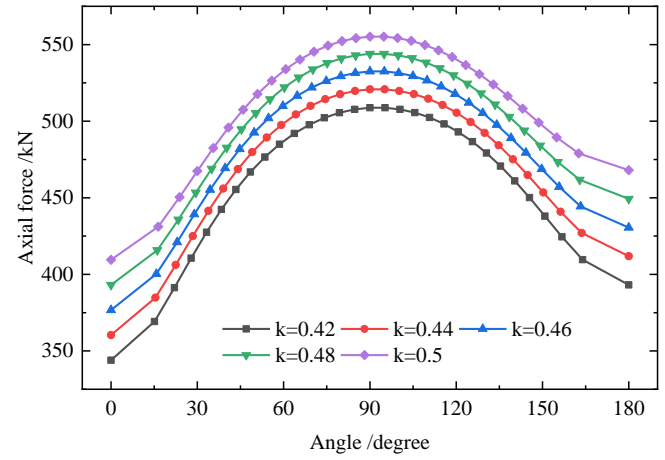

(a)

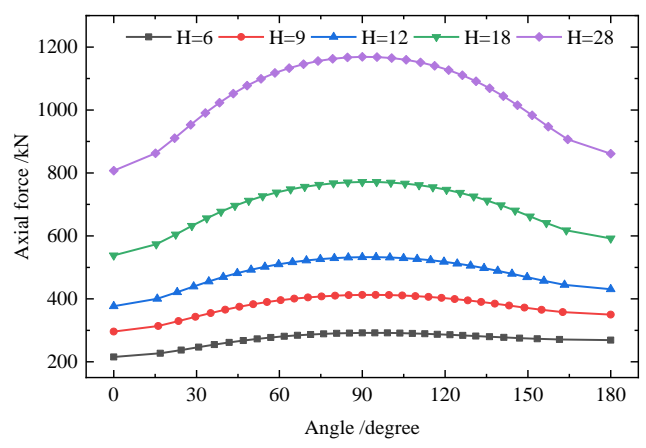

(b)

Figure 13. Axial force for zero bending moment shield tunnel with vertical diameter of $6 \mathrm{~m}$ : (a) Different coefficients of lateral earth pressure; (b) Different thickness of overlaying soil. 


\subsection{Cross-Section Design for the Minimum Bending Moment Shield Tunnel}

The above analysis indicates that the cross-section of the zero bending moment shield tunnel is related to the assumed earth pressure. However, usually one metro line only adopts one tunnel cross-section in light of practical construction, and tunnel buried depth and soil properties of the ground are changed along the metro line. Therefore, it is necessary to evaluate the earth pressure mode and corresponding length for the shield tunnel. Suppose the shield tunnel has $n$ kinds of engineering conditions, which are shown in Table 4 . Taking every condition into account, the cross-section axis of the minimum bending moment shield tunnel can be calculated as Equation (21).

$$
y=\frac{y_{1} l_{1}+y_{2} l_{2}+y_{3} l_{3}+\ldots \ldots+y_{n} l_{n}}{L}
$$

in which $L$ is the total length of the metro shield tunnel and is calculated as Equation (22).

$$
L=l_{1}+l_{2}+l_{3}+\ldots \ldots+l_{n}
$$

where $y_{i}$ refers to Equation (8) and can be calculated as Equation (23).

$$
y_{i}=f\left(P_{1-i}, P_{2-i}, P_{3-i}, l_{i}\right)
$$

Table 4. Design parameters for different engineering conditions.

\begin{tabular}{ccccc}
\hline Engineering Condition & $\boldsymbol{P}_{\mathbf{1}}$ & $\boldsymbol{P}_{\mathbf{2}}$ & $\boldsymbol{P}_{\mathbf{3}}$ & $\boldsymbol{l}$ \\
\hline 1 & $P_{1-1}$ & $P_{2-1}$ & $P_{3-1}$ & $l_{1}$ \\
2 & $P_{1-2}$ & $P_{2-2}$ & $P_{3-2}$ & $l_{2}$ \\
3 & $P_{1-3}$ & $P_{2-3}$ & $P_{3-3}$ & $l_{3}$ \\
$\ldots \ldots$ & $\ldots \ldots$ & $\ldots \ldots$ & $\ldots \ldots$ & $\ldots \ldots$ \\
$n$ & $P_{1-n}$ & $P_{2-n}$ & $P_{3-n}$ & $l_{4}$ \\
\hline
\end{tabular}

In order to apply the cross-section design theory of the minimum bending moment shield tunnel, this proposed design flow chart is presented as Figure 14.

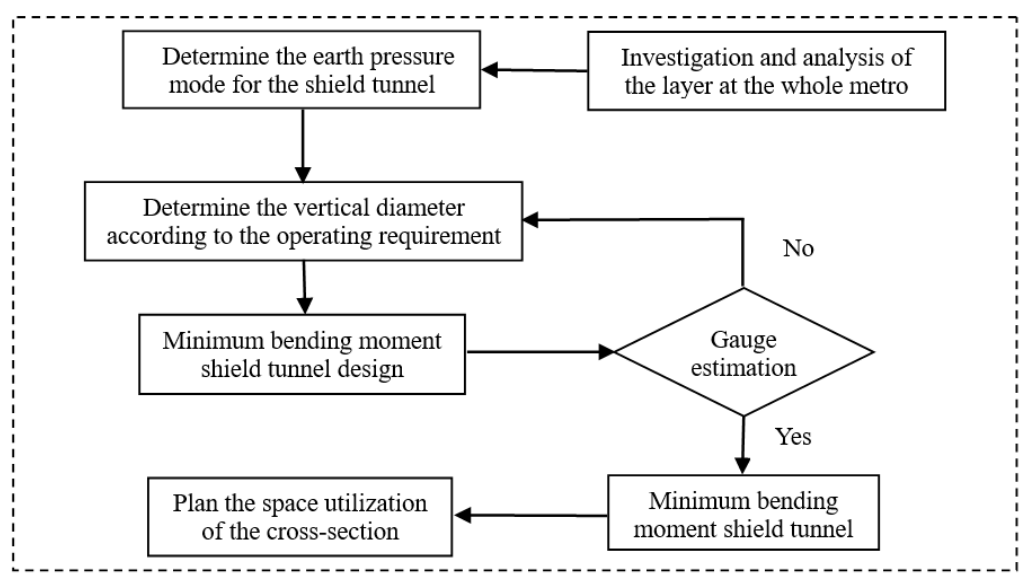

Figure 14. Design flow chart for shield tunnel using the concept of minimum bending moment.

\subsection{Case Analysis for Minimum Bending Moment Shield Tunnel}

The shield tunnel of one metro line in Shanghai passes through soft soil (3), (4), (5), and (6), as shown in Table 1, all of which feature a small soil-resistance coefficient, so it is important to consider reducing the bending moment as much as possible. According to the line design, the thickness of the overlying soil ranged between 6.5 and $28.8 \mathrm{~m}$, combined with the geological investigation data of the tunnel, several designs have been made based 
on the different working conditions for the shield tunnel of this metro line. The crosssection parameters of the zero bending moment shield tunnel under different working conditions were obtained as presented in Table 5. Finally, the cross-section of the shield tunnel conditional on the minimum bending moment is shown in Figure 15. The shape of the cross-section of the shield tunnel conditional on the minimum bending moment was similar to a vertical ellipse.

Table 5. Design parameters for different conditions.

\begin{tabular}{|c|c|c|c|c|c|c|c|c|c|c|c|c|c|}
\hline $\begin{array}{l}\text { Engineering } \\
\text { Condition }\end{array}$ & $H / \mathrm{m}$ & $K$ & $P_{1} / \mathrm{kPa}$ & $P_{2} / \mathrm{kPa}$ & $P_{3} / \mathrm{kPa}$ & $l / \mathrm{m}$ & $a / \mathrm{m}$ & $b / \mathrm{m}$ & $c / \mathrm{m}$ & $N_{1} / \mathbf{k N}$ & $N_{2} / \mathbf{k N}$ & $N_{3} / \mathbf{k N}$ & $\Delta / \mathrm{m}$ \\
\hline 1 & 7 & 0.429 & 136.50 & 58.56 & 50.19 & 2755 & 6.00 & 4.697 & 4.703 & 225.87 & 276.06 & 320.98 & 0.1489 \\
\hline 2 & 10 & 0.429 & 195.00 & 83.66 & 50.19 & 5933 & 6.00 & 4.481 & 4.484 & 301.16 & 351.35 & 437.20 & 0.1149 \\
\hline 3 & 10 & 0.493 & 195.00 & 96.14 & 57.68 & 4340 & 6.00 & 4.803 & 4.807 & 346.09 & 403.77 & 468.67 & 0.1149 \\
\hline 4 & 13 & 0.429 & 253.50 & 108.75 & 50.19 & 2045 & 6.00 & 4.360 & 4.362 & 376.45 & 426.64 & 552.88 & 0.0935 \\
\hline 5 & 13 & 0.493 & 253.50 & 124.98 & 57.68 & 6473 & 6.00 & 4.674 & 4.676 & 432.61 & 490.29 & 592.68 & 0.0935 \\
\hline 6 & 16 & 0.493 & 312.00 & 153.82 & 57.68 & 5423 & 6.00 & 4.591 & 4.592 & 519.13 & 576.81 & 716.42 & 0.0788 \\
\hline 7 & 16 & 0.449 & 312.00 & 140.09 & 52.53 & 2807 & 6.00 & 4.381 & 4.383 & 472.80 & 525.33 & 683.70 & 0.0788 \\
\hline 8 & 19 & 0.493 & 370.50 & 182.66 & 57.68 & 680 & 6.00 & 4.533 & 4.534 & 605.65 & 663.33 & 840.00 & 0.0681 \\
\hline 9 & 19 & 0.449 & 370.50 & 166.35 & 52.53 & 1470 & 6.00 & 4.326 & 4.327 & 551.60 & 604.13 & 801.64 & 0.0681 \\
\hline 10 & 22 & 0.449 & 429.00 & 192.62 & 52.53 & 1620 & 6.00 & 4.286 & 4.287 & 630.40 & 682.93 & 919.49 & 0.0599 \\
\hline 11 & 25 & 0.429 & 487.50 & 209.14 & 50.19 & 784 & 6.00 & 4.159 & 4.160 & 677.61 & 727.80 & 1013.92 & 0.0535 \\
\hline 12 & 28 & 0.429 & 546.00 & 234.23 & 50.19 & 1980 & 6.00 & 4.135 & 4.136 & 752.90 & 803.09 & 1129.02 & 0.0483 \\
\hline
\end{tabular}

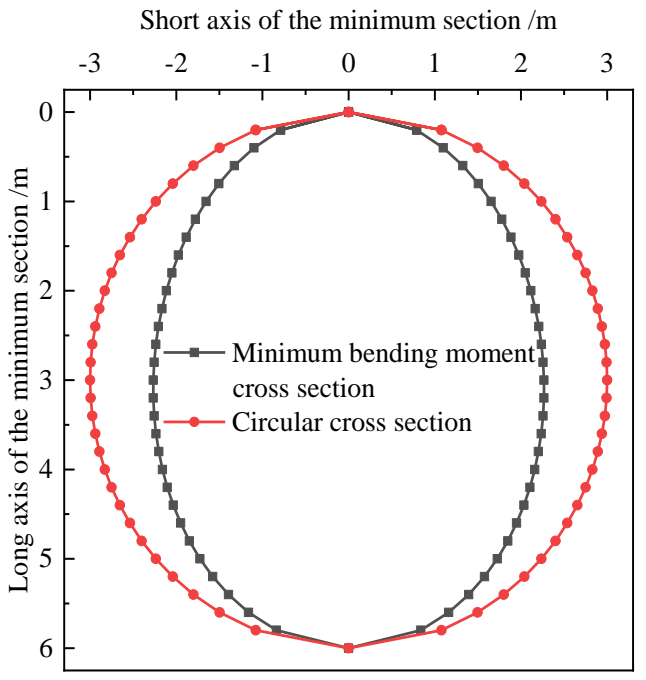

Figure 15. Comparison between minimum bending moment shield tunnel cross-section and circular shield tunnel cross-section in Shanghai.

The finite element software Midas GTS NX was adopted for the numerical simulation analysis in order to compare the bending moments of two differently shaped shield tunnel cross-sections due to the surrounding earth pressure shown in Figure 15 (take the bending moment for the tension on the inner side of the tunnel as positive). With reference to one metro line in Shanghai that travels through soft soil areas, simulation analysis was conducted for four working conditions, where the thickness of the overlying soil of the shield tunnel was $7 \mathrm{~m}, 13 \mathrm{~m}, 19 \mathrm{~m}$, and $25 \mathrm{~m}$. Due to the constant cross-section shape of the shield tunnel, the 2D model was utilized to simulate the cross-section bending moment $[29,30]$. The 2D plane strain model was utilized to simulate the different soils, and the soil constitutive model was a modified Mohr-Coulomb model. The soil parameters and material properties were the same as those of the soft area of the above-mentioned metro line in Shanghai, as shown in Table 6. The beam element model was utilized to simulate the tunnel lining with reference to the Shanghai metro shield tunnel in light of the 
dimension and mechanical parameters, as shown in Figure 11. The interaction between the tunnel and the soil was simulated using a compressed elastic spring, as shown in Figure 16, the vertical elliptical cross-section can be taken as an example.

Table 6. Soil mechanical parameters for different stratums.

\begin{tabular}{|c|c|c|c|c|c|c|c|c|}
\hline Soil Layer & Thickness/m & $\begin{array}{c}\text { Unit } \\
\text { Weight } \\
/ \mathbf{k N} / \mathrm{m}^{3}\end{array}$ & $\begin{array}{c}\text { Moisture } \\
\text { Content/\% }\end{array}$ & $\begin{array}{l}\text { Void } \\
\text { Ratio }\end{array}$ & Cohesion/kPa & $\begin{array}{l}\text { Internal } \\
\text { Friction } \\
\text { Angle }^{\circ}\end{array}$ & $\begin{array}{l}\text { Compression } \\
\text { Modu- } \\
\text { lus/MPa }\end{array}$ & $\begin{array}{c}\text { Poisson } \\
\text { Ratio }\end{array}$ \\
\hline Clay & 4.5 & 20.5 & 23.3 & 0.695 & 44 & 15.5 & 6.58 & 0.30 \\
\hline Mucky silty clay & 6.5 & 19.6 & 39.7 & 1.123 & 9 & 16.5 & 3.36 & 0.30 \\
\hline Mucky clay & 29 & 18.8 & 49.4 & 1.392 & 13 & 10.5 & 2.27 & 0.33 \\
\hline
\end{tabular}

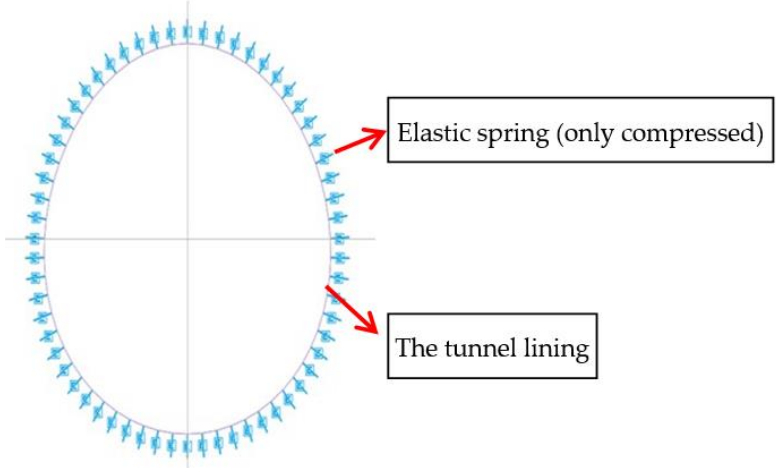

Figure 16. The interaction between the tunnel and the soil of the numerical simulation model.

The soil model of this article was designed to be $80 \mathrm{~m}$ wide and $40 \mathrm{~m}$ tall, constituted by three types of soil. From the top to the bottom, the soils were clay, mucky silty clay, and mucky clay and the thickness of the soils were $4.5 \mathrm{~m}, 11.5 \mathrm{~m}$, and $29 \mathrm{~m}$, respectively. The soil model was divided into 17,055 mixed grids. The radius of the circular cross-section tunnel model was $3 \mathrm{~m}$ and was divided into 38 grids through size control. The long-axis of the vertical elliptical cross-section tunnel model was $6 \mathrm{~m}$ long and the short-axis was $4.4 \mathrm{~m}$ long. It was divided into 62 grids through size control. The grid division of the numerical simulation model is shown in Figure 17.

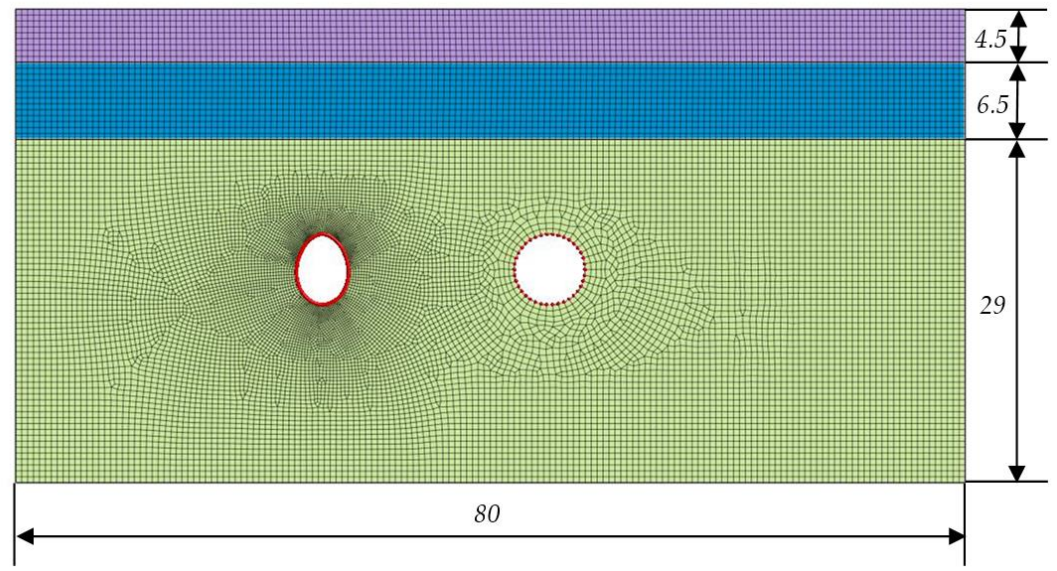

Figure 17. The grid division of the numerical simulation model (unit: $\mathrm{m}$ ).

The maximum bending moment and the minimum bending moment of the two differently shaped cross-sections of the tunnel under the different working condition were obtained using the simulation analysis, as shown in Table 7. It can be learnt through Table 7 that the bending moments of the two differently shaped cross-sections increased 
as the thickness of the overlying soil increased, and the bending moment increased more obviously in the case of the circular cross-section. As for the conditional on the same working condition, compared to the circular cross-section, the vertical elliptical crosssection featured a much smaller bending moment. Also, as the thickness of the overlying soil increased, the decrease in the bending moment of the vertical elliptical cross-section was more obvious.

Table 7. Maximum and minimum bending moments of two different bending moment shield tunnel cross-sections for different conditions.

\begin{tabular}{|c|c|c|c|c|c|}
\hline \multirow{2}{*}{$\begin{array}{l}\text { Engineering } \\
\text { Conditions }\end{array}$} & \multirow[b]{2}{*}{$\mathrm{H} / \mathrm{m}$} & \multicolumn{2}{|c|}{$\begin{array}{l}\text { Minimum Bending Moment } \\
\text { Shield Tunnel Cross-Section }\end{array}$} & \multicolumn{2}{|c|}{$\begin{array}{l}\text { Circular Shield Tunnel } \\
\text { Cross-Section }\end{array}$} \\
\hline & & $\begin{array}{c}\text { Max } \\
\text { Bending } \\
\text { Moment/kN·m }\end{array}$ & $\begin{array}{c}\text { Min } \\
\text { Bending } \\
\text { Moment/kN·m }\end{array}$ & $\begin{array}{c}\text { Max } \\
\text { Bending } \\
\text { Moment } / \mathbf{k N} \cdot \mathbf{m}\end{array}$ & $\begin{array}{c}\text { Min } \\
\text { Bending } \\
\text { Moment } / \mathrm{kN} \cdot \mathrm{m}\end{array}$ \\
\hline 1 & 7 & 218.644 & -164.328 & 362.403 & -327.64 \\
\hline 2 & 13 & 245.091 & -208.737 & 567.907 & -538.893 \\
\hline 3 & 19 & 331.966 & -275.233 & 779.613 & -755.177 \\
\hline 4 & 25 & 422.12 & -350.606 & 995.103 & -969.411 \\
\hline
\end{tabular}

When the thickness of the overlying soil of the tunnel was $25 \mathrm{~m}$, the bending moment diagram of two differently shaped cross-sections is shown in Figure 18. It can be seen from Figure 18 that the maximum values of the two differently shaped cross-sections both appear at the bottom of the tunnel arch, while the minimum bending moment values both appear at the waist of the tunnel. The maximum bending moment value of the circular crosssection tunnel was $995.103 \mathrm{kN} \cdot \mathrm{m}$ and the minimum bending moment value was -969.411 $\mathrm{kN} \cdot \mathrm{m}$. On the other hand, the maximum bending moment value of the vertical elliptical cross-section tunnel was $422.12 \mathrm{kN} \cdot \mathrm{m}$ and the minimum value was $-350.606 \mathrm{kN} \cdot \mathrm{m}$. When compared with the circular cross-section, the maximum bending moment of the vertical elliptical cross-section was $57.58 \%$ less while the minimum value was $67.83 \%$ less.

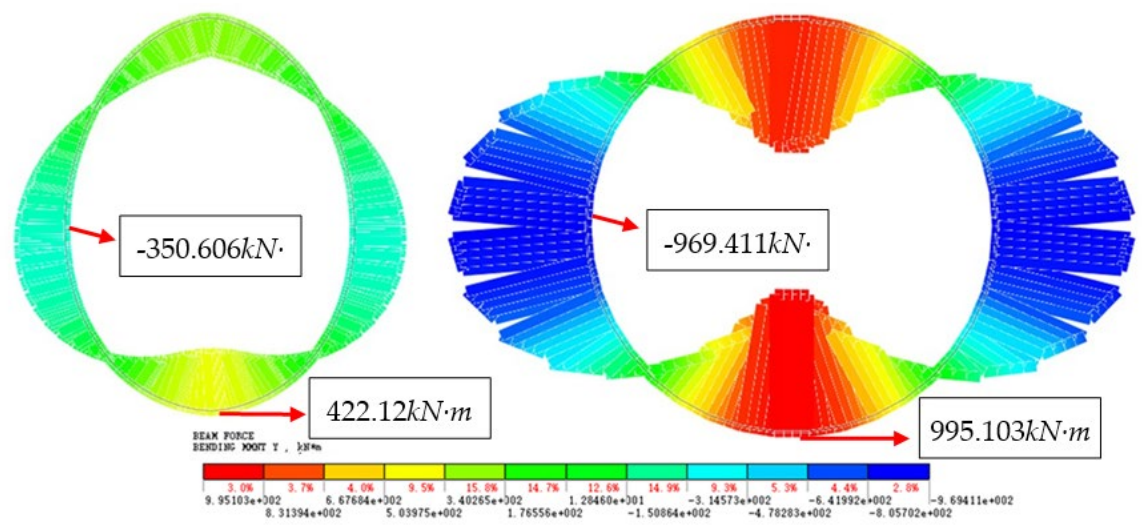

Figure 18. Comparison between minimum bending moment shield tunnel cross-section and circular shield tunnel cross-section in Shanghai.

The cross-section shape of the zero bending moment shield tunnel in this article was obtained by methods of rational assumptions. In addition, with the consideration that, normally, metro lines are constructed with only one shield tunnel of one cross-section, the weighted average method was used to obtain the minimum bending moment shield tunnel cross-section shape. As a result, the bending moment of the similar vertical elliptical cross-section shield tunnel obtained in the simulation was not zero. However, it can be learnt from the numerical simulation calculation, by means of the improvement of the cross-section shape of the tunnel, that the bending moment was significantly decreased compared to the circular tunnel, which makes it favorable both in the case of the transverse 
deformation of the tunnel structure and in the case of longitudinal segment joint failure. One of the Shanghai metro tunnels mainly passes through soft soil, so the soil resistance is small. It is necessary to design a rational cross-section to decrease the bending moment. According to the primary design drawing, the buried depth was from 6.5 to $28.8 \mathrm{~m}$. According to the geological investigation data, the engineering conditions were divided into 12 types, and the critical parameters of the cross-section for the corresponding zero bending moment shield tunnels were calculated, which are shown in Table 5. According to Equation (21), the minimum bending moment shield tunnel was obtained, as shown in Figure 15. The cross-section of minimum bending moment shield tunnel was similar to a vertical elliptical cross-section, and it is obviously different from the circle. Table 7 shows that with this shield tunnel, with this peculiar cross-section, its bending moment can be greatly reduced in soft soil area.

\section{Conclusions}

(1) Given that the bending moment of the cross-section of the shield tunnel constructed in the soft soil area tends to easily lead to beyond-limit oval deformation of the cross-section and induce diseases and waterproof failure in terms of the segment joint structure, this article puts forward the concept of designing a zero bending moment shield tunnel for the first time.

(2) Based on the characteristics of the surrounding rocks of the tunnel and rational assumption conditions, this article obtains the structural and mechanical calculation model of the rational axis for the zero bending moment shield tunnel and the expression of the rational axis. In addition, the internal force and key parameters calculating the equations of the zero bending moment shield tunnel are advised here in this article.

(3) Taking the shield tunnel constructed in the Shanghai soft soil area as an example, we designed and analyzed the zero bending moment shield tunnel. The results indicate that if the vertical diameter $a$ remains the same, as the lateral earth pressure coefficient $k$ increases, the center horizontal diameter $b$ and the maximum horizontal diameter $c$ both increase, but still less than the vertical diameter $a$; however, if the center horizontal diameter $b$ remains the same, as the buried height of the tunnel increases, the vertical diameter $a$ increases and the shear force of the zero bending moment shield tunnel is zero.

(4) Normally, one metro line can only use one shield tunnel with one cross-section shape. Given this, the shield tunnel cross-section design methods and procedures based on the minimum bending moment are proposed here. We took the parameters of the soils that one metro line shield tunnel in Shanghai passes through as an example and used the weighted average to obtain the minimum bending moment tunnel cross-section of that metro line. The numerical simulation analysis indicates that the similar vertical elliptical cross-section shield tunnel features a significantly smaller bending moment compared to that of the circular shield tunnel.

Author Contributions: Investigation of the actual utilization for different shield tunnel cross-sections, D.H. and H.J.; the proposal of the concept of zero bending moment, D.H. and C.X.; the proposal of the concept of minimum bending moment, D.H. and H.J.; rational and feasible hypotheses about zero bending moment, W.T. and X.L.; theoretical analysis for structural mechanical model of zero bending moment shield tunnel, D.H. and C.X.; data analysis of zero bending moment shield tunnel, H.J. and W.W.; numerical simulation of Shanghai minimum bending moment shield tunnel, D.H. and H.J. All authors have read and agreed to the published version of the manuscript.

Funding: This study was supported by the National Natural Science Foundation of China, grant number 52078213(the funder: Dawei, Huang), U1934208(the funder: Changjie, Xu) and 52178333(the funder: Wenbo, Tu) and Natural Science Foundation of Jiangxi Province, grant number 20192ACBL21003 (the funder: Dawei, Huang) and 20212BAB204013(the funder: Wenbo, Tu).

Institutional Review Board Statement: Not applicable. 
Informed Consent Statement: Not applicable.

Data Availability Statement: All data are available from the author.

Conflicts of Interest: The authors declare no conflict of interest.

\section{References}

1. Japan Society of Civil Engineers. Japanese Standard for Shield Tunneling; Japan Society of Civil Engineers: Tokyo, Japan, 1996.

2. Japan Society of Civil Engineers. Standard Specifications for Tunneling: Shield Tunnels; Japan Society of Civil Engineers: Tokyo, Japan, 2006.

3. Yukinori, K. Present status and technology of shield tunneling method in Japan. Tunn. Undergr. Space Technol. 2003, 18, 145-159. [CrossRef]

4. He, C.; Wang, B. Research progress and development trends of highway tunnels in China. J. Mod. Transp. 2013, 21, 209-223. [CrossRef]

5. Mashimo, H.; Ishimura, T. Evaluation of the load on shield tunnel lining in gravel. Tunn. Undergr. Space Technol. 2003, 18, 233-241. [CrossRef]

6. Blom, C.B.M. Design Philosophy of Concrete Linings for Tunnels in Soft Soils. Ph.D. Thesis, Technische Universiteit Delft, Delft, The Netherlands, 2002.

7. Bian, X.; Hong, Z.S.; Ding, J.W. Evaluating the effect of soil structure on the ground response during shield tunnelling in Shanghai soft clay. Tunn. Undergr. Space Technol. 2016, 58, 120-132. [CrossRef]

8. Vu, M.N.; Broere, W. Structural design model for tunnels in soft soils: From construction stages to the long-term. Tunn. Undergr. Space Technol. 2018, 78, 16-26. [CrossRef]

9. Working Group No. 2; International Tunnelling Association. Guidelines for the design of shield tunnel lining. Tunn. Undergr. Space Technol. 2000, 15, 303-331. [CrossRef]

10. General Administration of Quality Supervision, Inspection and Quarantine of the People's Republic of China. Code for Design of Metro GB 50157-2013; China Standards Press: Beijing, China, 2013.

11. Ding, W.Q.; Gong, C.J.; Mosalam, K.M.; Soga, K. Development and application of the integrated sealant test apparatus for sealing gaskets in tunnel segmental joints. Tunn. Undergr. Space Technol. 2017, 63, 54-68. [CrossRef]

12. Gong, C.J.; Ding, W.Q.; Mosalam, K.M.; Selim, G.; Soga, K. Comparison of the structural behavior of reinforced concrete and steel fiber reinforced concrete tunnel segmental joints. Tunn. Undergr. Space Technol. 2017, 68, 38-57. [CrossRef]

13. Do, N.A.; Dias, D.; Oreste, P.; Djeran-Maigre, I. The behaviour of the segmental tunnel lining studied by the hyperstatic reaction method. Eur. J. Environ. Civ. Eng. 2014, 18, 489-510. [CrossRef]

14. Huang, Z.; Fu, H.L.; Chen, W.; Zhang, J.B.; Huang, H.W. Damage detection and quantitative analysis of shield tunnel structure. Autom. Constr. 2018, 94, 303-316. [CrossRef]

15. Huang, D.W.; Zhou, S.H.; Feng, Q.S.; Liu, L.Y.; Zhang, P.F. Optimization for the longitudinal joint of metro shield tunnel under straight joint assembling in soft soli area. China Railw. Sci. 2017, 38, 62-69. (In Chinese) [CrossRef]

16. Gong, C.J.; Ding, W.Q.; Soga, K.; Mosalam, K.M. Failure mechanism of joint waterproofing in precast segmental tunnel linings. Tunn. Undergr. Space Technol. 2019, 84, 334-352. [CrossRef]

17. Gong, C.J.; Ding, W.Q.; Xie, D.W. Parametric investigation on the sealant behavior of tunnel segmental joints under water pressurization. Tunn. Undergr. Space Technol. 2020, 97, 103231. [CrossRef]

18. Lei, M.F.; Zhu, B.B.; Gong, C.J.; Ding, W.Q.; Liu, L.H. Sealing performance of a precast tunnel gasketed joint under high hydrostatic pressures: Site investigation and detailed numerical modeling. Tunn. Undergr. Space Technol. 2021, 115, 104082. [CrossRef]

19. Teachavorasinskun, S.; Chub-Uppakarn, T. Influence of segmental joints on tunnel lining. Tunn. Undergr. Space Technol. 2010, 25, 490-494. [CrossRef]

20. Guan, Z.C.; Deng, T.; Wang, G.; Jiang, Y.J. Studies on the key parameters in segmental lining design. J. Rock Mech. Geotech. Eng. 2015, 7, 674-683. [CrossRef]

21. Caratelli, A.; Meda, A.; Rinaldi, Z.; Giuliani-Leonardi, S.; Renault, F. On the behavior of radial joints in segmental tunnel linings. Tunn. Undergr. Space Technol. 2018, 71, 180-192. [CrossRef]

22. Wang, F.; Shi, J.K.; Huang, H.W.; Zhang, D.M. Modified analytical solution of shield tunnel lining considering nonlinear bending stiffness of longitudinal joint. Tunn. Undergr. Space Technol. 2020, 106, 103625. [CrossRef]

23. Bi, X.L.; Liu, X.; Wang, X.Z.; Lu, L.; Yang, Z.H. Experimental investigation on the ultimate bearing capacity of continuous-jointed segmental tunnel linings. China Civ. Eng. J. 2014, 47, 117-127. (In Chinese) [CrossRef]

24. Möller, S. Tunnel Induced Settlements and Structural Forces in Linings. Ph.D. Thesis, University of Stuttgart, Stuttgart, Germany, 2006.

25. Li, X.J.; Yan, Z.G.; Wang, Z.; Zhu, H.H. Experimental and analytical study on longitudinal joint opening of concrete segmental lining. Tunn. Undergr. Space Technol. 2015, 46, 52-63. [CrossRef]

26. Arnau, O.; Molins, C. Three dimensional structural response of segmental tunnel linings. Eng. Struct. 2012, 44, 210-221. [CrossRef]

27. Huang, D.W.; Zhou, S.H.; Lai, G.Q.; Feng, Q.S.; Liu, L.Y. Mechanism and character for deterioration of shield tunnel under surface surcharge. Chin. J. Geotech. Eng. 2017, 39, 1173-1181. (In Chinese) [CrossRef] 
28. Di, H.G.; Zhou, S.H.; Yao, X.P.; Tian, Z.Y. In situ grouting tests for differential settlement treatment of a cut-and-cover metro tunnel in soft soils. Bull. Eng. Geol. Environ. 2021, 80, 6415-6427. [CrossRef]

29. Hao, X.J.; Zhang, Q.; Sun, Z.W.; Wang, S.H.; Yang, K.; Ren, B.; Yu, G.F.; Zhou, W.; Chen, B.L.; Zhang, X.Y. Effects of the major principal stress direction respect to the long axis of a tunnel on the tunnel stability: Physical model tests and numerical simulation. Tunn. Undergr. Space Technol. 2021, 114, 103993. [CrossRef]

30. Kumar, J.; Jain, H. Elasto-plastic ground settlement response and stability of single and twin circular unsupported and supported tunnels. Transp. Geotech. 2021, 30, 100620. [CrossRef] 